\title{
Stage IIIA Appendix Carcinoma AJCC v8
}

National Cancer Institute

\section{Source}

National Cancer Institute. Stage IIIA Appendix Carcinoma A/CC v8. NCI Thesaurus. Code C134126.

Stage IIIA includes: (T1, N1, M0); (T2, N1, M0). T1: T umor invades the submucosa (through the muscularis mucosa but not into the muscularis propria). T2: Tumor invades the muscularis propria. N1: One to three regional lymph nodes are positive (tumor in lymph node measuring $0.2 \mathrm{~mm}$ or more) or any number of tumor deposits is present, and all identifiable lymph nodes are negative. M0: No distant metastasis. (AJCC 8th ed.) 